\title{
ARTICLE OPEN Discovery of SARS-CoV-2-E channel inhibitors as antiviral candidates
}

Yi Wang ${ }^{1,2}$, Sui Fang ${ }^{1}$, Yan $W^{3}{ }^{3}$ Xi Cheng ${ }^{1,2}$, Lei-ke Zhang ${ }^{3}$, Xu-rui Shen ${ }^{1,2}$, Shuang-qu Li ${ }^{1,2}$, Jian-rong Xu ${ }^{4,5}$, Wei-juan Shang ${ }^{3}$, Zhao-bing Gao ${ }^{1,2,6}$ and Bing-qing $\mathrm{Xia}^{1,2}$

Lack of efficiency has been a major problem shared by all currently developed anti-SARS-CoV-2 therapies. Our previous study shows that SARS-CoV-2 structural envelope (2-E) protein forms a type of cation channel, and heterogeneously expression of 2-E channels causes host cell death. In this study we developed a cell-based high throughput screening (HTS) assay and used it to discover inhibitors against 2-E channels. Among 4376 compounds tested, 34 hits with cell protection activity were found. Followed by an anti-viral analysis, 15 compounds which could inhibit SARS-CoV-2 replication were identified. In electrophysiological experiments, three representatives showing inhibitory effect on 2-E channels were chosen for further characterization. Among them, proanthocyanidins directly bound to $2-\mathrm{E}$ channel with binding affinity $\left(K_{\mathrm{D}}\right)$ of $22.14 \mu \mathrm{M}$ in surface plasmon resonance assay. Molecular modeling and docking analysis revealed that proanthocyanidins inserted into the pore of 2-E N-terminal vestibule acting as a channel blocker. Consistently, mutations of Glu 8 and Asn 15, two residues lining the proposed binding pocket, abolished the inhibitory effects of proanthocyanidins. The natural product proanthocyanidins are widely used as cosmetic, suggesting a potential of proanthocyanidins as disinfectant for external use. This study further demonstrates that 2-E channel is an effective antiviral drug target and provides a potential antiviral candidate against SARS-CoV-2.

Keywords: SARS-CoV-2; envelope protein (2-E); cation channel; high-throughput screening (HTS); anti-virus

Acta Pharmacologica Sinica (2022) 43:781-787; https://doi.org/10.1038/s41401-021-00732-2

\section{INTRODUCTION}

As the SARS-CoV-2 pandemic unfolds across the globe, more than 100 million people have been diagnosed and 3 million deaths have been reported worldwide. Similar to the earlier SARS and MERS beta coronaviruses (SARS-CoV, MERS-CoV), SARS-CoV-2 primarily infects alveolar epithelial cells of the lung and contributes to multiple organs failure and even death [1, 2]. Though vaccines and neutralizing antibodies are the most promising treatments currently [3, 4], looking for small molecule drugs is a long-term way for therapy. Among the 2036 clinical trials till October 2020,73\% of cases are associated with small molecule drugs development [5]. There are two categories for potential anti-coronavirus therapies. One targets SARS-CoV-2 itself and the other acts on the host immune system or host cell $[6,7]$. As a novel coronavirus, SARS-CoV-2 contains four structural proteins, nonstructural proteins, and some accessory proteins [8-11]. To date, targeting viral itself to discover potential drugs has obtained certain achievements in the progress of fighting against coronavirus. For example, remdesivir, an RNA-dependent RNA polymerase inhibitor, blocks the replication of virus [12]. Lopinavir/ ritonavir and GRL0617, inhibitors of viral protease, inhibit virus maturation [13, 14]. Similarly, baicalin and baicalein, the main protein $\left(M^{\text {pro }}\right)$ inhibitors, also exhibit antiviral activity $[15,16]$. In addition, some traditional Chinese medicines such as Lianhuaqingwen, were reported to reduce viral replication and improve the clinical symptoms of COVID-19 through its high inhibitory effect on human angiotensin-converting enzyme 2 (hACE2) [17-19]. On the other side, drugs that target host cells, such as dexamethasone, hydroxychloroquine, and chloroquine have been used for the treatment of COVID-19 perhaps through enhancing the innate immune system and attenuating the inflammatory response [20-22]. Plitidepsin, a eukaryotic elongation factor $1 \mathrm{~A}$ (eEF1A) inhibitor, exhibited potent preclinical efficiency against SARS-CoV-2 [23]. Though many potential drugs partly have anticoronavirus effects in animal infection models and have been evaluated in ongoing clinical trials, there is no specific drug for COVID-19 currently. Partial broad-spectrum antiviral drugs that have been used clinically were withdrawn for various reasons or only used in emergency situations. For instance, hydroxychloroquine has been withdrawn by the US Food and Drug Administration due to its strong side effects, such as heart rhythm disturbances [24]. Remdesivir shortens the time to recovery in mild patients whereas has no effect in severe patients [25]. Dexamethasone only modestly reduces mortality of patients who

\footnotetext{
${ }^{1}$ CAS Key Laboratory of Receptor Research, Stake Key Laboratory of Drug Research, Shanghai Institute of Materia Medica, Chinese Academy of Sciences, Shanghai 201203, China; ${ }^{2}$ University of Chinese Academy of Sciences, Beijing 100049, China; ${ }^{3}$ State Key Laboratory of Virology, Wuhan Institute of Virology, Center for Biosafety Mega-Science, Chinese Academy of Sciences, Wuhan 430071, China; ${ }^{4}$ Academy of Integrative Medicine, Shanghai University of Traditional Chinese Medicine, Shanghai 201203 , China; ${ }^{5}$ Department of

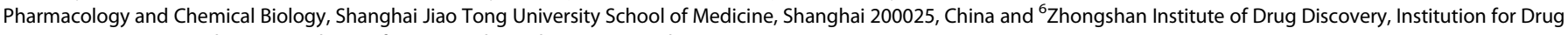
Discovery Innovation, Chinese Academy of Science, Zhongshan 528400, China

Correspondence: Wei-juan Shang (shangweijuan@wh.iov.cn) or Zhao-bing Gao (zbgao@simm.ac.cn) or Bing-qing Xia (xiabingqing@simm.ac.cn)

These authors contributed equally: Yi Wang, Sui Fang, Yan Wu.
}

Received: 23 February 2021 Accepted: 29 June 2021

Published online: 22 July 2021 
are receiving respiratory support [26]. Thus, discovery of effective targets and specific drugs with low side effects is still extremely urgent.

Previously, we have demonstrated that SARS-CoV-2 envelope protein (2-E) forms a type of cation channel and leads to host cell death [27]. We also found that the 2-E channel inhibitors are able to protect host cells from damage and exhibit anti-SARSCoV-2 activity, suggesting a possibility of identifying antiviral hits through evaluating cell-protective efficiency of compounds. Accordingly, we developed and carried out a high throughput screening (HTS) assay to find antiviral candidates targeting 2-E protein.

\section{MATERIALS AND METHODS}

Plasmid and compound libraries

The 2-E sequence was synthesized by the Beijing Genomics Institute (BGl, China). Vector pET28a and pcDNA5 were used for protein purification and cell transfection, respectively. Point mutations were generated using site-directed mutagenesis and confirmed by sequencing. Totally 4376 small molecules from multiple libraries were screened, including the US compound library ( 1200 compounds), the LJ compound library ( 800 compounds), the Chinese National Compound Library ( 2300 compounds). Veliparib (HY-10129, CAS No. 912444-00-9), wortmannin (HY-10197, CAS No. 19545-26-7), proanthocyanidins (HYN0794, CAS No. 4852-22-6) were purchased from MedChemExpress (MCE, NJ, USA).

\section{Cell culture}

Vero E6 cells were purchased from National Collection of Authenticate Cell Cultures (China). Vero E6 cells were grown in 90\% DMEM basal medium (11054001, Gibco, NY, USA) supplemented with $10 \%$ fetal bovine serum (10100, Gibco, NY, USA) and 100 units/mL penicillin/streptomycin (15070063, Gibco, NY, USA). Cells were grown at $37^{\circ} \mathrm{C}, 5 \% \mathrm{CO}_{2}$ incubator, and passaged approximately every 2 days when confluency up to $80 \%-90 \%$.

\section{High throughput screening assay}

For the first round of primary screening, Vero E6 cells were seeded in 96-well plates with 4,000 cells per well overnight. In the next day, $10 \mu \mathrm{M}$ compounds were pre-incubated with Vero E6 cells for $6 \mathrm{~h}$ with duplicate wells, then we transfected Vero E6 cells with $400 \mathrm{ng} /$ well 2-E plasmids using Lipofectamine 3000 Transfection Reagent (L3000015, Thermo Fisher, MA, USA). After $24 \mathrm{~h}$ (the third day), we tested cell viability by CCK-8 kit (40203ES60, Yeasen, China) according to the manufacturer's instructions. For the second round, we transfected Vero E6 cells first, after $6 \mathrm{~h}$ added 10 $\mu \mathrm{M}$ compounds with six repeats, and tested cell viability by CCK-8 kit $24 \mathrm{~h}$ later. For cytotoxicity assay, only $10 \mu \mathrm{M}$ compounds were incubated with Vero E6 cells for $24 \mathrm{~h}$. Absorbance analysis were performed with Thermo Scientific Microplate Reader at $450 \mathrm{~nm}$ according to the manufacturer's instructions (Thermo Fisher, MA, USA). Cell Protection $\%=\left(A_{\text {control }}-A_{\text {drug }}\right) /\left(A_{\text {control }}-A_{\text {model }}\right) \%$. $A_{\text {control, }}, A_{\text {drug, }}$ and $A_{\text {model }}$ represented absorbance value of three groups respectively at $450 \mathrm{~nm}$ via CCK-8 assay. The control group was Vero E6 cells transfected with $400 \mathrm{ng} /$ well pcDNA5 vector plasmids alone. The model group was Vero E6 cells transfected with $400 \mathrm{ng} /$ well 2-E plasmids alone. The drug group means the compounds treated Vero E6 cells with $400 \mathrm{ng} /$ well 2-E plasmids transfection.

Single-channel electrophysiological recording

The 2-E protein was expressed in E. coli BL21/DE3 pLysS cells and purified with Ni-NTA column, referred to our previous description [27]. Then purified 2-E protein was incorporated into lipid bilayers to examine the channel inhibition of compounds. All the lipids were bought from Avanti (850356P, 850408P, Avanti Polar Lipids,
AL, USA). The membrane lipids consist of phosphatidylcholines/ phosphatidylserine $=3 / 2$. The buffer contained $500 \mathrm{mM} \mathrm{KCl}$ in cis $/ 50 \mathrm{mM} \mathrm{KCl}$ in trans, all solutions were buffered by $5 \mathrm{mM}$ HEPES, $\mathrm{pH}=6.35$. Detailedly, proteins were added to cis side. Agitation and electrochemical gradients induced 2-E to combine with lipid membrane. Membrane currents were recorded under voltageclamp mode using a Warnner bilayer clamp amplifier BC-535 (Warner Instruments, MA, USA), filtered at $1-2 \mathrm{kHz}$. The recording frequency was $10 \mathrm{kHz}$. The currents were digitized using pClamp 10.2 software (Molecular Devices, CA, USA). The single-channel conductance was determined by fitting to Gaussian functions (bin width $=0.25 \mathrm{pA}$ ) and the open time was determined by fitting to single or bi-exponential equations. Open times less than 0.5-1.5 ms were ignored. Channel inhibition $\%=\left(1-P_{\mathrm{o}}\right.$, drug $/ P_{\mathrm{o}}$, control $) \%$. $P_{\mathrm{o}}$, control and $P_{\mathrm{o}}$, drug represented 2-E channel open probability before and after drug treatment. $P_{\mathrm{o}}$, the probability of channel being open, for the currents from a single channel was defined from the amplitude histogram as the ratio of the area from open channels to the total area.

\section{Antiviral efficiency test for compounds}

Vero E6 cells were seeded in 48-well plate with $4 \times 10^{4}$ cells per well overnight. The next day, compounds diluted as $10 \mu \mathrm{M}$ were incubated with the cells for $1 \mathrm{~h}$ at $37^{\circ} \mathrm{C}$. Then SARS-CoV-2 (isolatenCoV-2019BetaCoV/Wuhan/WIV04/2019) (about 400 PFU in $10 \mu \mathrm{L}$ DMEM, $\mathrm{MOI}=0.01$ ) was added. Twenty-four hours later, cell supernatants were taken for viral copies detection as usual. Viral RNA was isolated with MiniBEST Viral RNA/DNA Extraction Kit (9766 A, Takara, Japan) as the instruction described, and transcribed with PrimeScript ${ }^{\mathrm{TM}} \mathrm{RT}$ reagent Kit with gDNA Eraser (RR047B, Takara, Japan). Viral copies were quantified from viral CDNA by RT-PCR (Takara TB Green Premix Ex Taq ${ }^{\mathrm{TM}}$ II, Takara, Japan) with a standard curve method on $A B I 7500$ (Applied Biosystems 7500, CA, USA). The sequences of primers targeting SARS-CoV-2 S gene were as follows: F: $5^{\prime}$-CAATGGTTTAACAGGCA CAGG-3'; R: 5'-CTCAAGTGTCTGTGGATCACG-3'. Antiviral efficiency (Inhibition \%) $=\left(1-V_{\text {drug }} / V_{\text {control }}\right) \% . V$, represented viral copies. The control group and drug group were defined as $1 \%$ DMSO or compounds were incubated with Vero E6 cells for $1 \mathrm{~h}$ at $37^{\circ} \mathrm{C}$, then Vero E6 cells were infected with SARS-CoV-2 (about 400 PFU in $10 \mu \mathrm{L}$ DMEM, MOI $=0.01$ ). After $24 \mathrm{~h}$, cell supernatants were taken for viral copies via qRT-PCR.

\section{Molecular docking}

The solid-state NMR structure of SARS-CoV-2 envelope protein (PDB code: 7K3G) [28] was used as the docking receptor. A ligand was docked to the receptor using Schrodinger Glide software in SP mode with extended sampling. Searches were performed using Lamarckian Genetic Algorithm with default settings. A ligand was initially placed in the center of the binding site. Its center of mass was constrained to move within $1 \mathrm{~nm}$ diameter sphere, where it was allowed moving freely during the docking process. The docking model with the lowest binding energy was selected for analysis.

\section{SPR assay}

Biacore T200 instruments (GE Healthcare, UK) were used to evaluate the binding affinity of compounds to 2-E protein via SPR, as previously described [29]. Briefly, 2-E protein was immobilized on the surface of CM5 chip by using amine-coupling approach at a

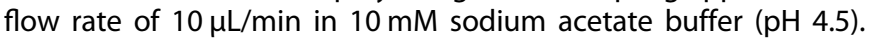
The sensor surface was activated with a 7 min injection of the mixture of $50 \mathrm{mM} \mathrm{N}$-hydroxysuccinimide (NHS) and $200 \mathrm{mM} \mathrm{1-}$ ethyl-3-(3-dimethylaminopropyl) carbodiimide. Then $50 \mu \mathrm{g} / \mathrm{mL}$ of Tau protein was injected to reach the target level of around 1400 $\mathrm{RU}$ and the surface was blocked with $1 \mathrm{M}$ ethanolamine, $\mathrm{pH} 8.5$. Series concentrations (typically 12.5, 25, 50, 100, $200 \mu \mathrm{M}$ ) of compounds were injected into the flow system and analyzed for 
a

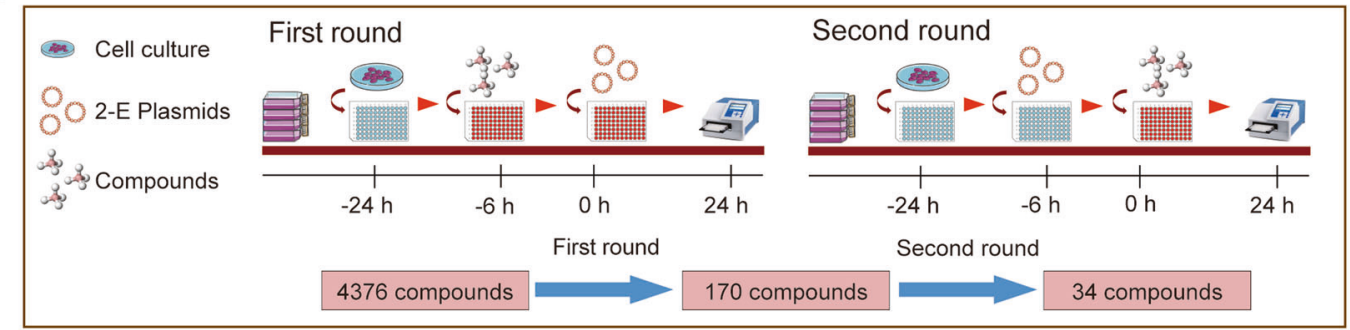

b

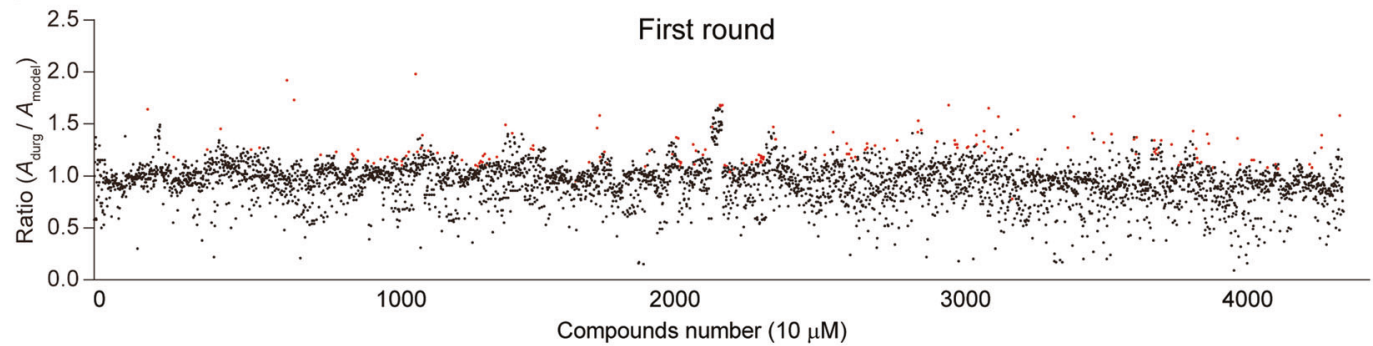

C
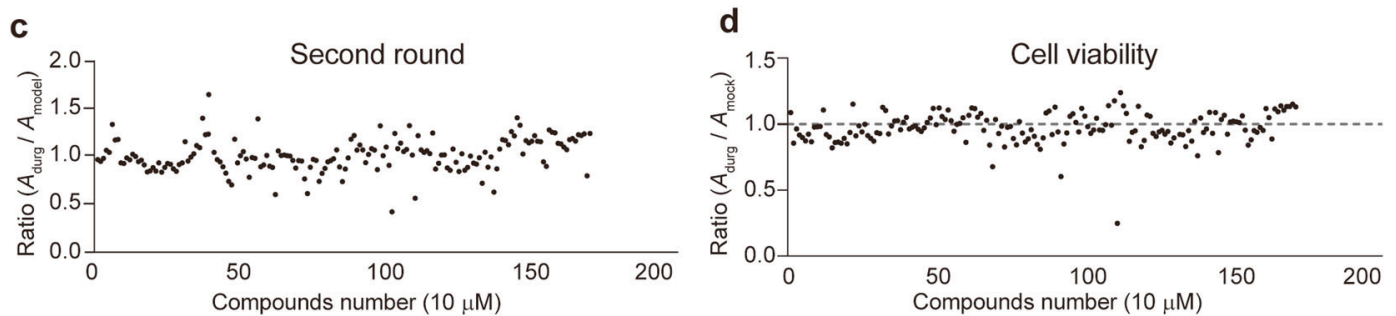

Fig. 1 Primary screening identified hits with protection activity against 2-E-induced cell death. a Schematic of cell based high throughput screening assay. b Overview of first round result. All compounds (4376) and their corresponding activity are represented by circle. The cell viability ratio of $A_{\text {drug }} / A_{\text {model }}$ displayed along the vertical axis. Top five to eight compounds with a ratio greater than 1 in each plate were considered as effective inhibitors and were displayed in red circle. Data represent the mean of the duplicate results. c Cellular protective ratio of secondary round screening $\left(170\right.$ hits). Data represent the mean of the six repeats. $A_{\text {model, }}$ the absorbance of 2-E transfected cells with DMSO treatment group. $A_{\text {drug, }}$ the absorbance of 2-E transfected cells with $10 \mu \mathrm{M}$ drug treatment group. d Cell viability ratio of 170 positive compounds. Data represent the mean of the six repeats. $A_{\text {drug }}$ the absorbance of $10 \mu \mathrm{M}$ drug treatment group. $A_{\text {mock }}$ the absorbance of DMSO treatment group.

$90 \mathrm{~s}$, and the dissociation was $120 \mathrm{~s}$. All binding analysis was performed in phosphate-buffered saline with $0.05 \%(\mathrm{v} / \mathrm{v})$ Tween20 and $1 \%$ DMSO, pH 7.4, at $25^{\circ} \mathrm{C}$. Prior to analysis, double reference subtractions were made to eliminate bulk refractive index changes, injection noise, and data drift. The binding affinity was determined by fitting to a Langmuir 1:1 binding model within the Biacore Evaluation software (GE Healthcare, UK).

Statistical analysis

The data are presented as the mean \pm SEM. The dose-effect curve was fitted using the Hill equation.

\section{RESULTS}

Primary screening identified hits with protection activity against 2E-induced cell death

We established a HTS assay by measuring protection activity of compounds against 2-E induced cell death. In the first round of the primary screening, Vero E6 cells were pre-incubated with 10 $\mu \mathrm{M}$ compounds and then transfected with 2-E plasmids. After 24 $h$, we assessed cell viability by measuring the change of absorbance $(A)$ in the presence or absence of compounds (Fig. 1a). We defined the cell viability ratio of $A_{\text {drug }} / A_{\text {model }}>1$ as an effective compound. After the first round, 170 (3.9\%) compounds were considered as pre-hits among 4376 tested compounds (Fig. 1b, red circles). Considering expression inhomogeneous of 2-E due to the variation of transient transfection efficiency among different plates, top five to eight compounds from each plate were selected for re-evaluation. Instead of pre-incubation, in the second round of the primary screening, $10 \mu \mathrm{M}$ compounds were applied $6 \mathrm{~h}$ after transient transfection (Fig. 1c). Only those compounds showing protective activity in both two rounds were considered as effective. In addition, those compounds that promoting cell proliferation were further removed from the hit list (Fig. 1d). Finally, 34 hits $(0.8 \%)$ with protection activity against 2-E induced cell death were identified (Table 1).

Secondary screening verified hits with antiviral activity and 2-E channel inhibition ability

Thirty-four hits with antiviral efficiency against SARS-CoV-2 were evaluated in the secondary screening. Vero E6 cells were pretreated with $10 \mu \mathrm{M}$ compound for $1 \mathrm{~h}$, then infected with virus $(\mathrm{MOI}=0.01)$. Dimethyl sulfoxide (DMSO, $1 \%$ ) was used as control. Inhibition efficacy was evaluated by measuring viral copy numbers in the cell supernatant via qRT-PCR. Defined inhibition > $20 \%$ as the standard, 15 compounds significantly suppressed SARS-CoV-2 replication (Fig. 2a). Subsequently, the inhibitory activity of these compounds on 2-E channels was further examined using the planar lipid bilayer (BLM) system. We defined the protein added side as cis side and the opposite as trans side (Fig. 2b,c). After ion channel conductance was detected, $100 \mu \mathrm{M}$ compounds were added to the trans side while stirring to facilitate binding of the compound to the channel. Three of the antiviral compounds, wortmannin, proanthocyanidins, and veliparib, were 
Table 1. Summary of cell protection, channel inhibition, and antiviral activity of 34 compounds.

\begin{tabular}{|c|c|c|c|}
\hline Compound name & $\begin{array}{l}\text { Channel } \\
\text { inhibition } \\
(100 \mu \mathrm{M})\end{array}$ & $\begin{array}{l}\text { Cellular } \\
\text { protection } \\
(10 \mu \mathrm{M})\end{array}$ & $\begin{array}{l}\text { Antiviral } \\
\text { activity } \\
\text { (inhibition } \\
\%, 10 \mu \mathrm{M} \text { ) }\end{array}$ \\
\hline 2-Deoxy-D-glucose & - & 1.34 & $<20$ \\
\hline Talazoparib & - & 1.43 & $20-40$ \\
\hline Veliparib & + & 1.34 & $>40$ \\
\hline Carsalame & - & 1.13 & $>40$ \\
\hline Gossypol-acetic acid & - & 1.41 & $>40$ \\
\hline Salvianolic acid B & - & 1.39 & $<20$ \\
\hline GW4869 & - & 1.29 & $20-40$ \\
\hline Wortmannin & + & 1.30 & $>40$ \\
\hline Demethyl & - & 1.18 & $>40$ \\
\hline $\mathrm{COH} 29$ & - & 1.28 & $>40$ \\
\hline IPA-3 & - & 1.27 & $<20$ \\
\hline BMS-626529 & - & 1.21 & $<20$ \\
\hline AT101 & - & 1.36 & $20-40$ \\
\hline Quercetin & - & 1.26 & $20-40$ \\
\hline Kartogenin & - & 1.27 & $20-40$ \\
\hline Edoxaban & - & 1.35 & $<20$ \\
\hline Rifamycin sodium & + & 1.21 & $<20$ \\
\hline Midecamycin & + & 1.20 & $<20$ \\
\hline Dihydroartemisinin & + & 1.37 & $<20$ \\
\hline Proanthocyanidins & + & 1.92 & $20-40$ \\
\hline Artemisinin & + & 1.22 & $20-40$ \\
\hline Artesunate & - & 1.49 & $<20$ \\
\hline Phenindione & - & 1.20 & $<20$ \\
\hline $\begin{array}{l}\text { Dihydroergotamine } \\
\text { mesylate }\end{array}$ & + & 1.14 & $<20$ \\
\hline Evans blue & - & 1.58 & $<20$ \\
\hline Streptomycin sulfate & - & 1.18 & $<20$ \\
\hline Nafronyl oxalate & + & 1.24 & $<20$ \\
\hline Dimethyl fumarate & + & 1.14 & $<20$ \\
\hline Valdecoxib & + & 1.37 & $<20$ \\
\hline $\begin{array}{l}\text { Chloropyramine } \\
\text { hydrochloride }\end{array}$ & - & 1.36 & $>40$ \\
\hline ABT-199 (GDC-0199) & - & 1.22 & $20-40$ \\
\hline Sapogenins Glycosides & - & 1.15 & $<20$ \\
\hline Carbamazepine & - & 1.17 & $<20$ \\
\hline Oxybutynin & - & 1.47 & $<20$ \\
\hline
\end{tabular}

found to effectively inhibit 2-E channel currents (Fig. 2d). Wortmannin is currently used as a pharmacological tool compound. Proanthocyanidins are a class of natural products. Being an antitumor drug, veliparib is currently in phase III clinical trial.

Validation of proanthocyanidins as an antiviral candidate targeting 2-E channels

To explore whether the channel inhibitory activity of the three compounds was due to direct binding, the SPR assay was performed. Dose-dependent binding of proanthocyanidins with 2-E proteins was observed (Fig. 3a). The binding interaction exhibited a fast association rate and a slow dissociation rate, indicating that proanthocyanidins presented relatively strong affinity for 2-E proteins. The response units at equilibrium were plotted against the proanthocyanidins concentration, and the dissociation constant $\left(K_{\mathrm{D}}\right)$ was calculated by fitting these data to fit curves through non-linear regression analysis. The results showed that proanthocyanidins bound to $2-\mathrm{E}$ with a $K_{\mathrm{D}}$ value of $22.14 \mu \mathrm{M}$ (Fig. 3a). In contrast, at equivalent molar ratios, wortmannin and veliparib exhibited weak or undetectable binding with 2-E proteins (Supplementary Fig. S1).

Then, proanthocyanidins were chosen for further evaluation. We found that proanthocyanidins dose-dependently suppressed 2-E induced Vero E6 cell death, 2-E channel currents, and the virus replication (Fig. 3b). The $\mathrm{IC}_{50}$ of proanthocyanidins were $94.4 \mu \mathrm{M}$, $0.94 \mu \mathrm{M}, 12.5 \mu \mathrm{M}$ for cell protection, channel inhibition, antiviral activity, respectively. Noticeably, under tested concentrations, no significant cytotoxicity was detected $\left(\mathrm{CC}_{50}>500 \mu \mathrm{M}\right)$ (Supplementary Fig. S1c). In addition, we also evaluated proanthocyanidins effects on 2-E channel induced macroscopic currents under symmetric potassium solutions via BLM. After 2-E channel incorporated in lipids, we added different concentrations of proanthocyanidins in trans side. The macroscopic currents were inhibited depending on the proanthocyanidins concentrations (Fig. 3c) with an $\mathrm{IC}_{50}=8.15 \mu \mathrm{M}$. Molecular docking of proanthocyanidins against the solid-state NMR structure of 2-E channel was carried to investigate how proanthocyanidins interact with the channels [28]. The docking model showed that the proanthocyanidins bind to the $\mathrm{N}$-terminal vestibule of the 2-E protein, suggesting the compound may inhibit cation conduction by steric occlusion of the pore. In the $\mathrm{N}$-terminal vestibule of $\mathrm{E}$ protein, four different residues (E8, T11, L12, and N15) from different subunits constitute a binding pocket of the proanthocyanidins (Fig. 3d). The docking poses of the proanthocyanidins showed that their chromane-5,7-diol group inserts into the pore of the $\mathrm{E}$ protein and forms putative hydrogen bonds with a polar residue N15. Linked to the chromane-5,7-diol group of the compound, the benzene-1,2-diol group attaches to the edge of the binding pocket consisting of T11 and L12 and forms putative hydrogen bonds with a negatively charged residue E8 (Fig. $3 \mathrm{~d})$. The rest part of the compound (i.e., 2-(3,4-dihydroxyphenyl) chromane-3,4,5,7-tetraol group) lies on the mouth of the pore and forms multiple putative hydrogen bonds with the charged residues E8 from different subunits. To validate the proposed binding site of proanthocyanidins, we designed single-point mutations engaging four residues mentioned above (2- $\mathrm{E}^{\mathrm{E} B \mathrm{~A}}$, $2-\mathrm{E}^{\mathrm{T} 11 \mathrm{~A}}, 2-\mathrm{E}^{\mathrm{L} 12 \mathrm{~A}}$ and $2-\mathrm{E}^{\mathrm{N} 15 \mathrm{~A}}$ ) and tested inhibitory capability of proanthocyanidins on these mutants. $2-\mathrm{E}^{\mathrm{E} 8 \mathrm{~A}}$ and $2-\mathrm{E}^{\mathrm{N} 15 \mathrm{~A}}$ mutations abolished the inhibitory effects of proanthocyanidins on the 2-E channel (Fig. 3e, Supplementary Figs. S2, S3), highly consistent with our molecular docking models. Taken together, these results validated proanthocyanidins as an antiviral candidate against SARS-CoV-2 targeting 2-E channels.

\section{DISCUSSION}

The absence of specific drugs against SRAS-CoV-2 has led humans to suffer the virus and major loss of economy for a long time [30, 31]. Drug discovery usually takes a long time and undergoes appropriate verification to ensure the safety and effectiveness of the drug. Under this circumstance, drugrepurposing is one of the attractive ways to find drugs for SARS-CoV-2 treatment. Our previous work found 2-E channel as an independent virulence factor not only causes the death of host cells but also participates in the life cycle of SARS-CoV-2 [27]. Based on the preliminary work, the current study revealed three major findings. First, we established a high throughput screening assay targeting cell lethal effect of 2-E channel; second, we discovered a 2-E channel inhibitor showing antiviral efficiency; third, our in vitro binding and simulation data highlighted proanthocyanidins binding pocket. 

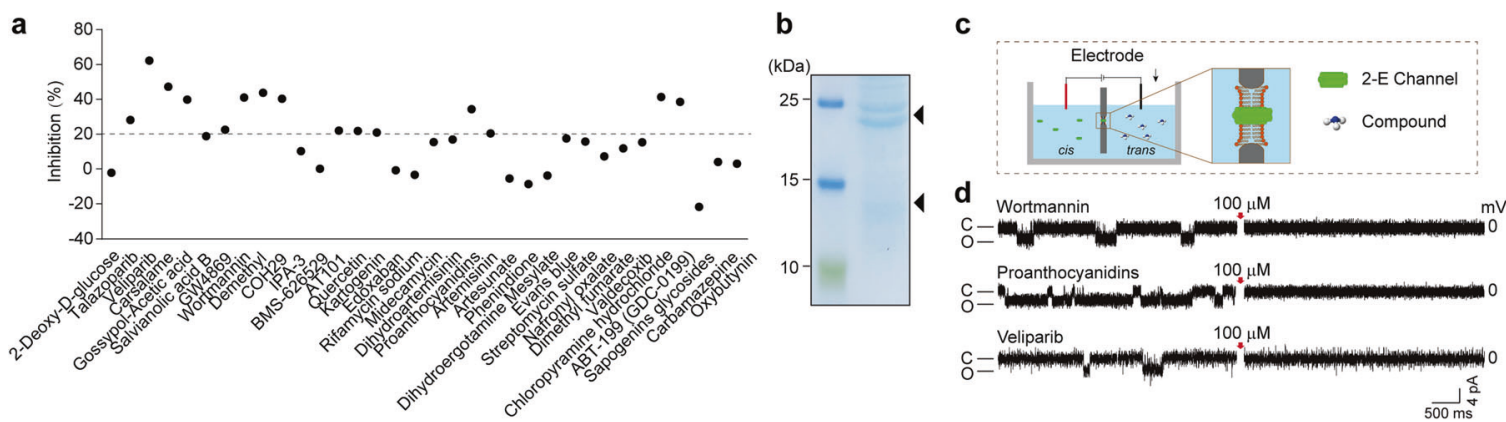

Fig. 2 Characters of 34 hits on anti-viral activity and 2-E channel inhibition ability. a Anti-SARS-CoV-2 efficiency of 34 hits at $10 \mu M$. Vero E6 cells were pre-treated with compounds for $1 \mathrm{~h}$, and then infected with SARS-CoV-2(MOI $=0.01)$. Viral copies were detected through qRT-PCR. b Purification of full-length 2-E protein with Ni-NTA affinity chromatography. $15 \%$ SDS-PAGE gel with coomassie blue staining. Triangle, 2-E proteins [27]. c Schematic of planar lipid bilayer system. d Representative single-channel traces after 2-E exposed to the indicated compounds at $100 \mu \mathrm{M}$. Once ion channel conductance was detected, compounds were added to the trans side while stirring to facilitate binding of the compound to the channel. The black arrow indicates the application of compounds $(n \geq 3)$. " $\mathrm{C}$ " means channel close; " $\mathrm{O}$ " means channel open.

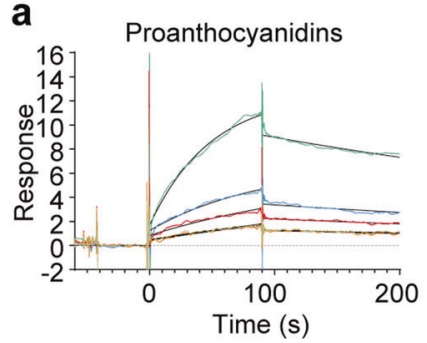

c

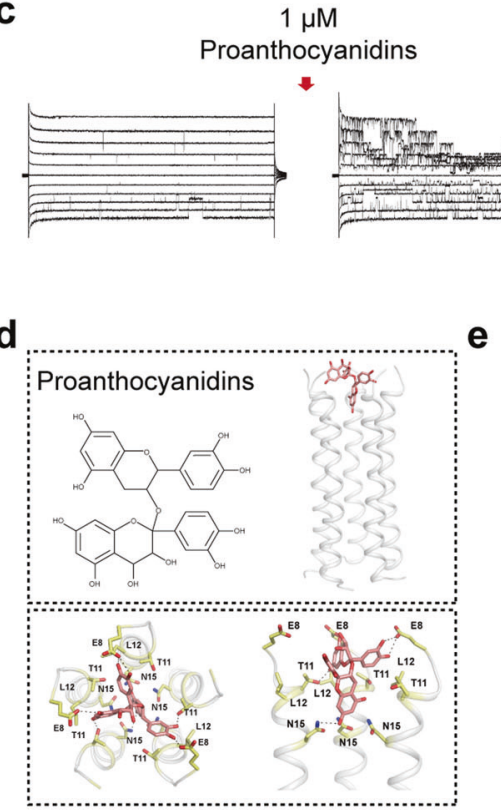

b Channel Inhibition

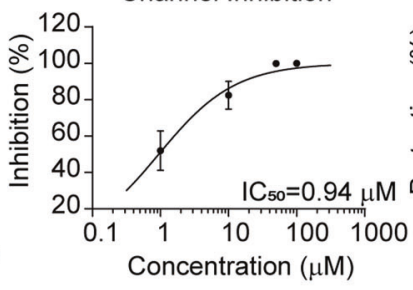

$50 \mu \mathrm{M}$ Proanthocyanidins
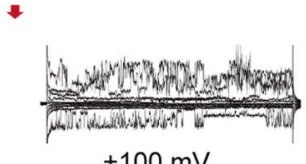

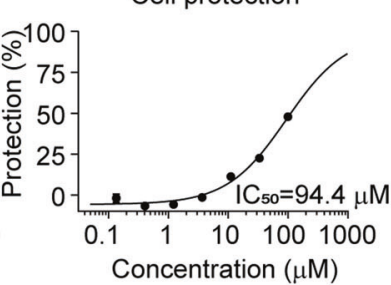

$100 \mu \mathrm{M}$

Proanthocyanidins

-

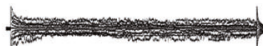

吕

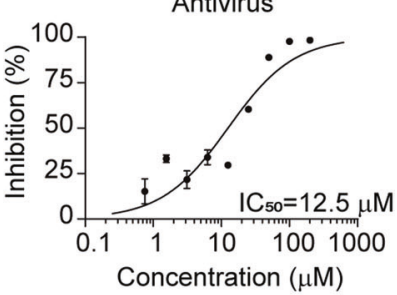

Macro-current Inhibition

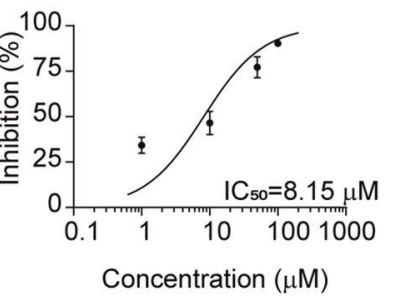

$100 \mu \mathrm{M}$

Proanthocyanidins

(
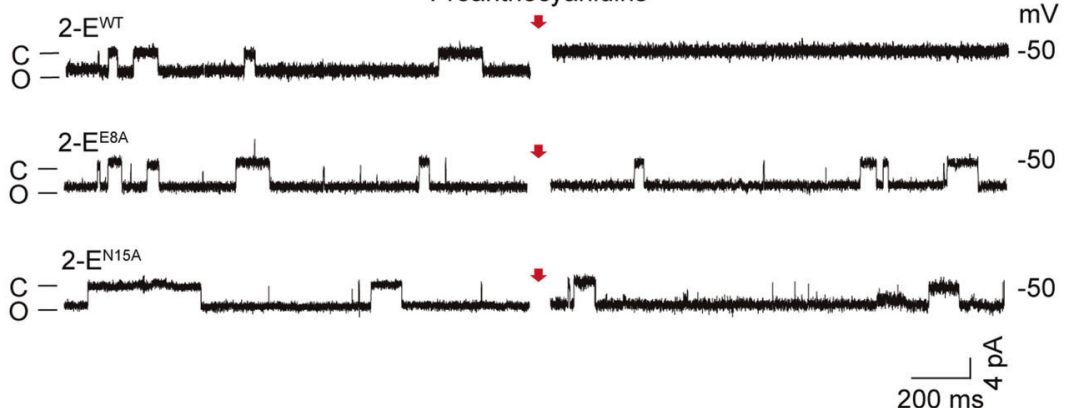

Fig. 3 The interaction mechanism of proanthocyanidins with the 2-E channel. a Binding ability of proanthocyanidins, wortmannin, and veliparib to 2 -E channel via SPR. b IC 50 of proanthocyanidins on cell protection, channel inhibition, and antivirus. c Proanthocyanidins inhibited 2-E-induced macro-currents. Left, proanthocyanidins dose-dependently inhibited 2-E-induced macro-current. Right, $\mathrm{IC}_{50}$ of proanthocyanidins on macro-currents inhibition $(n=3)$. d A representative docking pose of proanthocyanidins. The protein was shown in cartoon depict. The compound and key residues are shown as sticks. The putative hydrogen bonds are shown as dash lines. e Representative single-channel traces after the indicated 2-E mutant channels exposed to $100 \mu \mathrm{M}$ proanthocyanidins at $-50 \mathrm{mV}$. Once ion channel conductance was detected, compounds were added to the trans side while stirring to facilitate binding of the compound to the channel. The red arrow indicates the application of compounds $(n \geq 3)$. " $\mathrm{C}$ " means channel close; "O" means channel open.

To date, HTS strategies have been widely used in drug discovery and three general HTS approaches were reported to discover potential anti-coronavirus treatment options [11, 32-35]. First, directly screen existing broad-spectrum antiviral drugs that have been used to treat other viruses. Second, screen and repurpose chemical libraries or database that contain known drug effects and known information, such as signal pathways, physiological and/or immune responses. Third, de novo discover new drugs 
based on the genome and biophysical understanding of the coronavirus $[32,36,37]$. These schemes were effective to find candidate molecules but still existed an imperfection. For instance, screening of existing broad-spectrum antiviral drugs is not specific and may bring many side effects. The inhibitors targeting host cell hACE2, an important regulator of systemic blood pressure and cardiovascular disease, might cause heart and blood toxicity [38]. Besides, the redevelopment of new drugs not only requires huge manpower, material resources, financial resources, but also spends a long period. The HTS by measuring the influence of compounds on 2-E-induced cell death exhibits advantages. First, 2-E channel is a target on virus itself which may avoid the potential side effects mediated by host cell targets. Second, CCK-8 based method is easy to carry out and permits us obtaining a large amount of effective data quickly. The current pilot screening demonstrated the cell-based HTS is a promising strategy to discover antiviral candidates.

Proanthocyanidins are known as condensed tannins that are widely identified in various plants [39]. It has been endorsed to possess significant antioxidant capacities and owned various pharmacological properties. On one hand, proanthocyanidins have been developed as a skincare product with anti-wrinkle, sunscreen, and whitening abilities [40,41]. On the other hand, proanthocyanidins has therapeutic effects on a variety of diseases, such as cardiovascular diseases, neurological diseases and tumors [42-46]. It is worth to note, proanthocyanidins could inhibit the growth of liver cancer cells through specifically block Kv10.1 channel [47]. Very recently, virtual screening found proanthocyanidins could inhibit main protease $\left(\mathrm{M}^{\text {pro }}\right)$ activity of SARS-CoV-2, whereas lacked of antiviral activity evidence. In addition, many researchers reported proanthocyanidins antiviral effects including rotavirus, herpes simplex virus, coxsackie $B 3$ virus, and hepatitis $C$ virus [48-51]. Here, we first reported proanthocyanidins acting as a 2-E channel blocker weakens SARS-CoV-2 replication in vitro which works at a micromolar concentration of $12.5 \mu \mathrm{M}$. To decipher the working of the drug and mechanism of inhibition at the molecular level, we investigated protein-drug interactions via SPR and docking. The SPR finding suggests that the good affinity of proanthocyanidins with 2-E channel. Molecular modeling studies give solid support to the fact that proanthocyanidins bind to pore pocket of 2-E channel N-terminal. In addition, our molecular modeling and electrophysiological data demonstrated that proanthocyanidins interact with E8 and N15 residues, which are critical pore-facing position amino acids [28].

The structural envelope (E) protein shares striking functional similarities in different coronaviruses, including SARS-CoV, MERS-CoV [52]. In addition to the essential roles of 2-E channel we identified, it has been found that deletion of $E$ channel results in attenuating SARS-CoV pathogenesis [53-55]. Beyond that, E channel was also found to participate in MERS-CoV assembling, virion release, and pathogenesis [56, 57]. Thus, the small molecules targeting SARSCoV-2 envelope protein could be potential broad-spectrum anticoronavirus drugs. The limitation of our study is lacked in vivo validation, which is mainly due to the scarcity of P3 Labs and we long for sharing our results immediately. In brief, we established an efficient screening system targeting 2-E channel and identified potential therapeutic candidates against SARS-CoV-2.

\section{ACKNOWLEDGEMENTS}

We are grateful to the National Science Fund of Distinguished Young Scholars (81825021), Fund of Youth Innovation Promotion Association (2019285), the National Natural Science Foundation of China (81773707, 31700732), Fund of Shanghai Science and Technology Innovation Action Plan (20ZR1474200), the National Key Research and Development Program of China (2020YFC0842000), the Strategic Leading Science and Technology Projects of Chinese Academy of Sciences (XDA12050308), Fund of National Science and Technology Major Project (2018ZX09711002-002-006) and the Hubei Science and Technology Project (2020FCA003) for financial support.

\section{AUTHOR CONTRIBUTIONS}

$\mathrm{BQX}, \mathrm{ZBG}$, and WJS conceived the project. BQX, ZBG, and LKZ designed the experiments; $Y$ Wang, SQL, and SF purified the proteins; $Y$ Wang performed the electrophysiological recordings; SF, BQX, and XRS carried out the cell-based assays; $Y$ $\mathrm{Wu}$ and WJS carried out the virus assays in vitro; JRX carried out SPR assays. XC carried out molecular docking. All authors analyzed and discussed the data. ZBG, BQX, Y Wang, and LKZ wrote the manuscript.

\section{ADDITIONAL INFORMATION}

Supplementary information The online version contains supplementary material available at https://doi.org/10.1038/s41401-021-00732-2

Competing interests: The authors declare no competing interests.

\section{REFERENCES}

1. de Wit E, van Doremalen N, Falzarano D, Munster VJ. SARS and MERS: recent insights into emerging coronaviruses. Nat Rev Microbiol. 2016;14:523-34.

2. Zhu N, Zhang D, Wang W, Li X, Yang B, Song J, et al. A novel coronavirus from patients with pneumonia in China, 2019. N Engl J Med. 2020;382:727-33.

3. Wu Y, Wang F, Shen C, Peng W, Li D, Zhao C, et al. A noncompeting pair of human neutralizing antibodies block COVID-19 virus binding to its receptor ACE2. Science. 2020;368:1274-8.

4. Shi R, Shan C, Duan X, Chen Z, Liu P, Song J, et al. A human neutralizing antibody targets the receptor-binding site of SARS-CoV-2. Nature. 2020;584:120-4.

5. Twomey JD, Luo S, Dean AQ, Bozza WP, Nalli A, Zhang B. COVID-19 update: the race to therapeutic development. Drug Resist Update. 2020;53:100733.

6. Liu X, Liu C, Liu G, Luo W, Xia N. COVID-19: progress in diagnostics, therapy and vaccination. Theranostics. 2020;10:7821-35.

7. Asselah T, Durantel D, Pasmant E, Lau G, Schinazi RF. COVID-19: discovery, diagnostics and drug development. J Hepatol. 2021;74:168-84.

8. Kim D, Lee JY, Yang JS, Kim JW, Kim VN, Chang H. The architecture of SARS-CoV-2 transcriptome. Cell. 2020;181:914-21.

9. Kang S, Yang $M$, Hong Z, Zhang L, Huang Z, Chen X, et al. Crystal structure of SARS-CoV-2 nucleocapsid protein RNA binding domain reveals potential unique drug targeting sites. Acta Pharm Sin B. 2020;10:1228-38.

10. Ghosh AK, Brindisi M, Shahabi D, Chapman ME, Mesecar AD. Drug development and medicinal chemistry efforts toward SARS-coronavirus and COVID-19 therapeutics. ChemMedChem. 2020;15:907-32.

11. Coelho C, Gallo G, Campos CB, Hardy L, Wurtele M. Biochemical screening for SARS-CoV-2 main protease inhibitors. PLoS One. 2020;15:e0240079.

12. Gordon CJ, Tchesnokov EP, Woolner E, Perry JK, Feng JY, Porter DP, et al. Remdesivir is a direct-acting antiviral that inhibits RNA-dependent RNA polymerase from severe acute respiratory syndrome coronavirus 2 with high potency. J Biol Chem. 2020;295:6785-97.

13. Gao X, Qin B, Chen P, Zhu K, Hou P, Wojdyla JA, et al. Crystal structure of SARSCoV-2 papain-like protease. Acta Pharm Sin B. 2021;11:237-45.

14. Uzunova K, Filipova E, Pavlova V, Vekov T. Insights into antiviral mechanisms of remdesivir, lopinavir/ritonavir and chloroquine/hydroxychloroquine affecting the new SARS-CoV-2. Biomed Pharmacother. 2020;131:110668.

15. Jo S, Kim S, Kim DY, Kim MS, Shin DH. Flavonoids with inhibitory activity against SARS-CoV-2 3CLpro. J Enzym Inhib Med Chem. 2020;35:1539-44.

16. Su HX, Yao S, Zhao WF, Li MJ, Liu J, Shang WJ, et al. Anti-SARS-CoV-2 activities in vitro of shuanghuanglian preparations and bioactive ingredients. Acta Pharmacol Sin. 2020;41:1167-77.

17. Chen $X$, Wu Y, Chen $C$, Gu Y, Zhu $C$, Wang $S$, et al. Identifying potential antiCOVID-19 pharmacological components of traditional Chinese medicine lianhuaqingwen capsule based on human exposure and ACE2 biochromatography screening. Acta Pharm Sin B. 2021;11:222-36.

18. Zeng $M, \mathrm{Li} L$, Wu Z. Traditional chinese medicine lianhua qingwen treating coronavirus disease 2019(COVID-19): Meta-analysis of randomized controlled trials. PLoS One. 2020;15:e0238828.

19. Runfeng $L$, Yunlong $H$, Jicheng $H$, Weiqi $P$, Qinhai $M$, Yongxia $S$, et al. Lianhuaqingwen exerts anti-viral and anti-inflammatory activity against novel coronavirus (SARS-CoV-2). Pharmacol Res. 2020;156:104761.

20. Cui C, Zhang M, Yao X, Tu S, Hou Z, Jie En VS, et al. Dose selection of chloroquine phosphate for treatment of COVID-19 based on a physiologically based pharmacokinetic model. Acta Pharm Sin B. 2020;10:1216-27.

21. Chen J, Liu D, Liu L, Liu P, Xu Q, Xia L, et al. A pilot study of hydroxychloroquine in treatment of patients with moderate COVID-19. J Zhejiang Univ Med Sci. 2020;49:215-9.

22. Ortolani C, Pastorello EA. Hydroxychloroquine and dexamethasone in COVID-19: who won and who lost? Clin Mol Allergy. 2020;18:17. 
23. White KM, Rosales R, Yildiz S, Kehrer T, Miorin L, Moreno E, et al. Plitidepsin has potent preclinical efficacy against SARS-CoV-2 by targeting the host protein eEF1A. Science. 2021;371:926-31.

24. Group RC, Horby P, Mafham M, Linsell L, Bell JL, Staplin N, et al. Effect of hydroxychloroquine in hospitalized patients with COVID-19. N Engl J Med. 2020; 383:2030-40.

25. Beigel JH, Tomashek KM, Dodd LE, Mehta AK, Zingman BS, Kalil AC, et al. Remdesivir for the treatment of COVID-19 - final report. N Engl J Med. 2020; 383:1813-26.

26. Group RC, Horby P, Lim WS, Emberson JR, Mafham M, Bell JL, et al. Dexamethasone in hospitalized patients with COVID-19 - preliminary report. N Engl J Med. 2020;384:693-704.

27. Xia B, Shen X, He Y, Pan X, Liu FL, Wang Y, et al. SARS-CoV-2 envelope protein causes acute respiratory distress syndrome (ARDS)-like pathological damages and constitutes an antiviral target. Cell Res. 2021;10:1-14.

28. Mandala VS, McKay MJ, Shcherbakov AA, Dregni AJ, Kolocouris A, Hong M. Structure and drug binding of the SARS-CoV-2 envelope protein in phospholipid bilayers. Nat Struct Mol Biol. 2020;27:1202-8.

29. Li J, Yu C, Wang R, Xu J, Chi Y, Qin J, et al. The omega-carboxyl group of 7ketocholesteryl-9-carboxynonanoate mediates the binding of oxLDL to CD36 receptor and enhances caveolin-1 expression in macrophages. Int J Biochem Cell Biol. 2017;90:121-35.

30. Abd El-Aziz TM, Stockand JD. Recent progress and challenges in drug development against COVID-19 coronavirus (SARS-CoV-2) - an update on the status. Infect Genet Evol. 2020;83:104327.

31. Liao H, Zhang L, Marley G, Tang W. Differentiating COVID-19 response strategies. Innovation. 2020;1:100003.

32. Zumla A, Chan JF, Azhar El, Hui DS, Yuen KY. Coronaviruse-drug discovery and therapeutic options. Nat Rev Drug Discov. 2016;15:327-47.

33. Ghafouri F, Cohan RA, Noorbakhsh F, Samimi H, Haghpanah V. An in-silico approach to develop of a multi-epitope vaccine candidate against SARS-CoV-2 envelope (E) protein. Res Sq. 2020; rs.3.rs-30374. https://doi.org/10.21203/rs.3.rs30374/v1.

34. Naik B, Gupta N, Ojha R, Singh S, Prajapati VK, Prusty D. High throughput virtual screening reveals SARS-CoV-2 multi-target binding natural compounds to lead instant therapy for COVID-19 treatment. Int J Biol Macromol. 2020; 160:1-17.

35. Smith E, Davis-Gardner ME, Garcia-Ordonez RD, Nguyen $\Pi$, Hull M, Chen E, et al. High-Throughput screening for drugs that inhibit papain-like protease in SARS CoV-2. SLAS Discov. 2020;25:1152-61.

36. Xian Y, Zhang J, Bian Z, Zhou H, Zhang Z, Lin Z, et al. Bioactive natural compounds against human coronaviruses: a review and perspective. Acta Pharm Sin B. 2020;10:1163-74

37. Wu C, Liu Y, Yang Y, Zhang P, Zhong W, Wang Y, et al. Analysis of therapeutic targets for SARS-CoV-2 and discovery of potential drugs by computational methods. Acta Pharm Sin B. 2020;10:766-88.

38. Anguiano L, Riera M, Pascual J, Soler MJ. Circulating ACE2 in cardiovascular and kidney diseases. Curr Med Chem. 2017;24:3231-41.

39. Rauf A, Imran M, Abu-Izneid T, lahtisham UIH, Patel S, Pan X, et al. Proanthocyanidins: a comprehensive review. Biomed Pharmacother. 2019;116:108999.

40. Saliou C, Rimbach G, Moini H, McLaughlin L, Hosseini S, Lee J, et al. Solar ultraviolet-induced erythema in human skin and nuclear factor-kappa-Bdependent gene expression in keratinocytes are modulated by a French maritime pine bark extract. Free Radic Biol Med. 2001;30:154-60.

41. Grether-Beck S, Marini A, Jaenicke T, Krutmann J. French maritime pine bark extract (Pycnogenol(R)) effects on human skin: clinical and molecular evidence. Ski Pharmacol Physiol. 2016;29:13-7.

42. de la Iglesia R, Milagro FI, Campion J, Boque N, Martinez JA. Healthy properties of proanthocyanidins. Biofactors. 2010;36:159-68.
43. Wang YJ, Thomas P, Zhong JH, Bi FF, Kosaraju S, Pollard A, et al. Consumption of grape seed extract prevents amyloid-beta deposition and attenuates inflammation in brain of an Alzheimer's disease mouse. Neurotox Res. 2009;15:3-14.

44. Huang S, Yang N, Liu Y, Gao J, Huang T, Hu L, et al. Grape seed proanthocyanidins inhibit colon cancer-induced angiogenesis through suppressing the expression of VEGF and Ang1. Int J Mol Med. 2012;30:1410-6.

45. Kampa M, Theodoropoulou K, Mavromati F, Pelekanou V, Notas G, Lagoudaki ED, et al. Novel oligomeric proanthocyanidin derivatives interact with membrane androgen sites and induce regression of hormone-independent prostate cancer. J Pharmacol Exp Ther. 2011;337:24-32.

46. Vaid M, Prasad R, Singh T, Jones V, Katiyar SK. Grape seed proanthocyanidins reactivate silenced tumor suppressor genes in human skin cancer cells by targeting epigenetic regulators. Toxicol Appl Pharmacol. 2012;263:122-30.

47. Na W, Ma B, Shi S, Chen Y, Zhang H, Zhan Y, et al. Procyanidin B1, a novel and specific inhibitor of Kv10.1 channel, suppresses the evolution of hepatoma. Biochem Pharmacol. 2020;178:114089.

48. Lipson SM, Ozen FS, Karthikeyan L, Gordon RE. Effect of pH on anti-rotavirus activity by comestible juices and proanthocyanidins in a cell-free assay system. Food Environ Virol. 2012;4:168-78.

49. Xu X, Xie H, Wang Y, Wei X. A-type proanthocyanidins from lychee seeds and their antioxidant and antiviral activities. J Agric Food Chem. 2010;58:11667-72.

50. Takeshita $M$, Ishida $Y$, Akamatsu $E$, Ohmori $Y$, Sudoh $M$, Uto $H$, et al. Proanthocyanidin from blueberry leaves suppresses expression of subgenomic hepatitis $C$ virus RNA. J Biol Chem. 2009;284:21165-76.

51. Iwasawa A, Niwano Y, Mokudai T, Kohno M. Antiviral activity of proanthocyanidin against feline calicivirus used as a surrogate for noroviruses, and coxsackievirus used as a representative enteric virus. Biocontrol Sci. 2009;14:107-11.

52. Schoeman D, Fielding BC. Coronavirus envelope protein: current knowledge. Virol J. 2019;16:69.

53. DeDiego ML, Álvarez E, Almazán F, Rejas MaT, Lamirande E, Roberts A, et al. A Severe acute respiratory syndrome coronavirus that lacks the $E$ gene is attenuated in vitro and in vivo. J Virol. 2007;81:1701-13.

54. Wilson L, Gage P, Ewart G. Hexamethylene amiloride blocks E protein ion channels and inhibits coronavirus replication. Virology. 2006;353:294-306.

55. Zhang X, Liu Y, Liu J, Bailey AL, Plante KS, Plante JA, et al. A trans-complementation system for SARS-CoV-2 recapitulates authentic viral replication without virulence. Cell. 2021;184:2229-38.

56. Surya W, Li Y, Verdia-Baguena C, Aguilella VM, Torres J. MERS coronavirus envelope protein has a single transmembrane domain that forms pentameric ion channels. Virus Res. 2015;201:61-66.

57. Almazan F, DeDiego ML, Sola I, Zuniga S, Nieto-Torres JL, Marquez-Jurado S, et al. Engineering a replication-competent, propagation-defective middle east respiratory syndrome coronavirus as a vaccine candidate. mBio. 2013;4:e00650-00613.

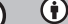

Open Access This article is licensed under a Creative Commons Attribution 4.0 International License, which permits use, sharing, adaptation, distribution and reproduction in any medium or format, as long as you give appropriate credit to the original author(s) and the source, provide a link to the Creative Commons license, and indicate if changes were made. The images or other third party material in this article are included in the article's Creative Commons license, unless indicated otherwise in a credit line to the material. If material is not included in the article's Creative Commons license and your intended use is not permitted by statutory regulation or exceeds the permitted use, you will need to obtain permission directly from the copyright holder. To view a copy of this license, visit http://creativecommons. org/licenses/by/4.0/.

(c) The Author(s) 2021 